\title{
SPEAKEASY LINKULES - PLUG COMPATIBLE SOFTWARE
}

Stan Cohen

Prepared for

Association for Computing Machinery

Seattle, Washington

October 16-19, 1977

This report was prepared as an account of work
sponsored by the United States Government. Neither the
United States nor the United States Department of
Energy, nor any of their employees, nor any of their
contractors, subcontractors, or their employees, makes
any warranty, express or implied, or assumes any legal
liability or responsibility for the accuracy, completeness
or usefulness of any information, apparatus, product or
process disclosed, or represents that its use would not
infringe privately owned rights.

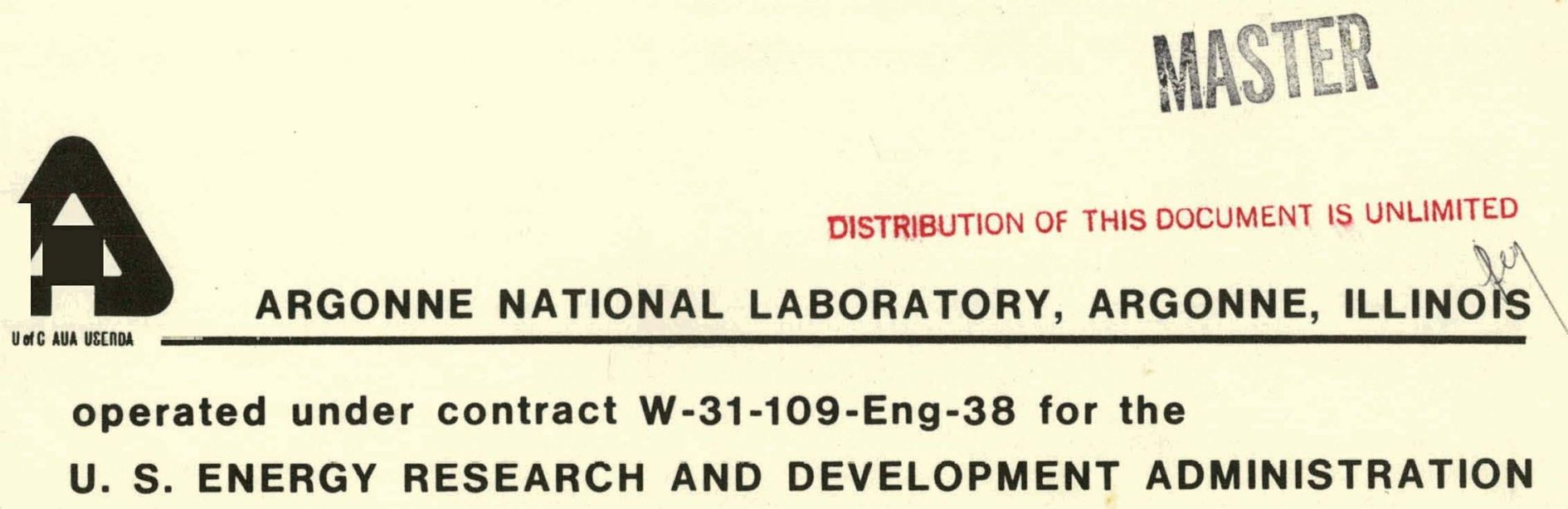




\section{DISCLAIMER}

This report was prepared as an account of work sponsored by an agency of the United States Government. Neither the United States Government nor any agency Thereof, nor any of their employees, makes any warranty, express or implied, or assumes any legal liability or responsibility for the accuracy, completeness, or usefulness of any information, apparatus, product, or process disclosed, or represents that its use would not infringe privately owned rights. Reference herein to any specific commercial product, process, or service by trade name, trademark, manufacturer, or otherwise does not necessarily constitute or imply its endorsement, recommendation, or favoring by the United States Government or any agency thereof. The views and opinions of authors expressed herein do not necessarily state or reflect those of the United States Government or any agency thereof. 


\section{DISCLAIMER}

Portions of this document may be illegible in electronic image products. Images are produced from the best available original document. 
The facilities of Argonne National Laboratory are owned by the United States Government. Under the terms of a contract (W-31-109-Eng-38) between the U. S. Energy Research and Development Administration, Argonne Universities Association and The University of Chicago, the University employs the staff and operates the Laboratory in accordance with policies and programs formulated, approved and reviewed by the Association.

\section{MFIMRFiRS OF ARGONNE, UNIVERSITIES ASSOCIATION}

The University of Arizona Carnegie-Mellon University Case Western Reserve University The University of Chicago University of Cincinnati IIlinois Institute of Technology University of Illinois Indiana University Iowa Statc University The University of Iowa
Kansas State University The University of Kansas Loyola University Marquette University Michigan State University The University of Mlichigan University of Minnesota University of Missouri Northwestern University University of Notre Dame
The Ohio State University

Ohio University

The Pennsylvania State University

Purdue University

Saint Louis University

Southern Illinois University

The University of Texas at Austin Washington University

Wayne State University

The University of Wisconsin

NOTICE

This report was prepared as an account of work sponsored by the United States Government. Neither the United States nor the United States Energy Research and Development Administration, nor any of their employees, nor any of their contractors, subcontractors, or their employees, makes any warranty, express or implied, or assumes any legal liability or responsibility for the accuracy, completeness or usefulness of any information, apparatus, product or process disclosed, or represents that its use would not infringe privately-owned rights. Mention of commercial products, their manufacturers, or their suppliers in this publication does not imply or connote approval or disapproval of the product by Argonne National Laboratory or the U. S. Energy Research and Development Administration. 


\author{
Speakeasy Linkules $\{$ plug. Compatible Softwaret
}

Stan Cohen

Argonne National Laboratory

\section{ABSTRACT}

A universal computer language must be able to evolve to satisfy the needs of its current and future users. This paper describes such a language, called speakeasy. The paper emphasizes those features of Speakeasy that relate to its naturalness and to its extensibility. Extensibility in the speakeasy sense means the ability to bring diverse sets of routines under the umbrella of the system and thus make them available to users. Interfacing a routine through the construction of a linkable module, called a linkule, extends the capabilities of speakeasy in a general and unrestricted way. The concept of the linkule is explained and illustrated by examplcs. In order to provide some background a few illustrative examples of the Speakeasy language are given.

\section{INTRODUCTION}

Speakeasy is a computer language that is designed with the primary goal of answering the needs of users. One means of attaining this goal is by providing a language syntax that closely parallels that of the user. Modeled on conventional mathematical notation, the speakeasy language is easily learned and tolerant of unimportant syntactical deviation. The language is therefore characterized by its naturalness and by its understanding. It is generally conceded that speakeasy is the easiest computer language to learn; a typical introductory lecture of only a few minutes is sufficient to enable even a complete computer novice to begin to carry out relevant and meaningful calculations.

That a language that is easily learned can at the same time be one of great power is perhaps less easily understood. None the less, it is rapidly becoming apparent that this language is one of the most powerful interactive computational languages currently in use and it will become even more potent in the future. This strength lies not in the language syntax but rather in the structure of the system in which the language processor resides.

Work performed under auspices of the U.S. Energy Research and Development Mdministration, Division of Physical Research.
Designed over a decade ago, the system is truly extensible; the structure itself enables more and more power to be made available without mocification of the basic processor. The growth tif the speakeasy system, manifested in the growtil of its vocabulary, is now clearly the major feature that attracts new groups of users.

The first section of this paper describes the basic Speakeasy language. Examples of the simplicity and naturalness of the language are given, primarily to demonstrate the overall atmosphere in which the user carries out the formulation of his problems. The second section involves the structure of the system. It is the disjoint nature of Speakeasy, the separation of the language processor from the mathematical operators of the system, that gives it its true power. The last section is a description of the interface to the linkules and a demonstration of the ease with which new abilities are added to the language. A sample of a linkule is supplied.

\section{SPEAKEASY - A COMPUTER LANGUAGE FOR PEOPLE}

The design of any computer language requires that certain decisions relating to efficiency, clairty etc. be made. In most cases such decisions reflect an attempt to provide the user with access to the real capabilities of the computing hardware. Languages such as $\mathrm{PL} / \mathrm{I}$ and Fortran let the bulk of the language specifications provide such information. The precision for numerical representation, the variety of data types and the means of formatting input and output are all related directly to the hardware of the computer. The difference between integer and floating point arithmetic, though of great importance in the actual implementation of the calculation, are not natural concepts to a person interested in formulating a problem for quick results. A Fortran diagnostic resulting from attempting to take the square root of an integer, though educational, hardly makes the computer more endearing. The rules that result in Fortran programs evaluating $3 / 2$ as 1 or $\mathrm{PL} / \mathrm{I}$ programs evaluating $25+1 / 3$ as $5.333 \ldots$, though meaningful to knowledgeable programmers, are not really natural to most people and represent an unnecessary burden to a casual computer user.

Speakeasy is designed with the needs of such casual users in mind. The overall objective is 
: to carry out the users stated problem with a minimum of hassle. The Speakeasy language specification is simple. If the statement is clearly and unambiguously specified, and it looks correct to the user, ther: it is the task of the processor to nroperly interpret that statement. While it is ot always possible to meet this simple specifivation, it is the philosophy implied that is important. Relieving that the user's prejudices are almost always right leads to the development of a language that is guaranteed to be acceptable to users.

The conventional approach to creating a language is to specify it before implementation. All ambiguities and uncertanties are resolved prior to actual construction of the language processor. While such an approach is clearly advantageous to the language implementors it suffers from the same basic problem that confronts the development of any. large predefined system. The first opportunity available for users of the system to provide meaningful feedback is after a major portion of the system is operating and much of the system is rigidly fixed. There is thus little opportunity for the eventual users of the program to influence the specifications of the system.

speakeasy has been a production language for many years. During that period, although used by many people, it has had no rigid language specification; rather it evolved under the influence of its users and has grown into a language that is highly readable and very understandable. While it might now be possible to completely specify speakeasy and its notation, it is believed that the lack of such specifications were important during the initial evolution of. the system. The capabilities of the processor have evolved greatly over the years of use, always in the direction of increased power but always with a concern for the users of the system and their real needs.

\section{EXAMPLES OF THE LANGUAGE}

Speakeasy is best learned by using it in an intexactive environment. In such usage it can be viewed as a powerful programmable desk calculator able to do simple computations and at the same time, a calculator rich in available facilities. In this section we will only illustrate some of its basic capabilities. Shown below is a sample of the simple desk calculator feature. The colon underscore (:_) is the speakeasy prompt indicator. It means that the processor is waiting for a request from the user. All user input is shown in lowercase letters on the lines beginning with :-. All other lines in the examples are output from speakeasy.

$$
\begin{aligned}
& : 2+2 \\
& 2+2=4 \\
& : \text { cuberoot (8) } \\
& \text { CUBEROOT (8) = } 2 \\
& \vdots \text { answer+2 } \\
& \text { ANSWER+2 }=4 \\
& : \quad x=9 \\
& \vdots x^{\star} x \\
& X^{*} X=81 \\
& : \quad x=1,2,2,3,4,5,6,7,8,3
\end{aligned}
$$

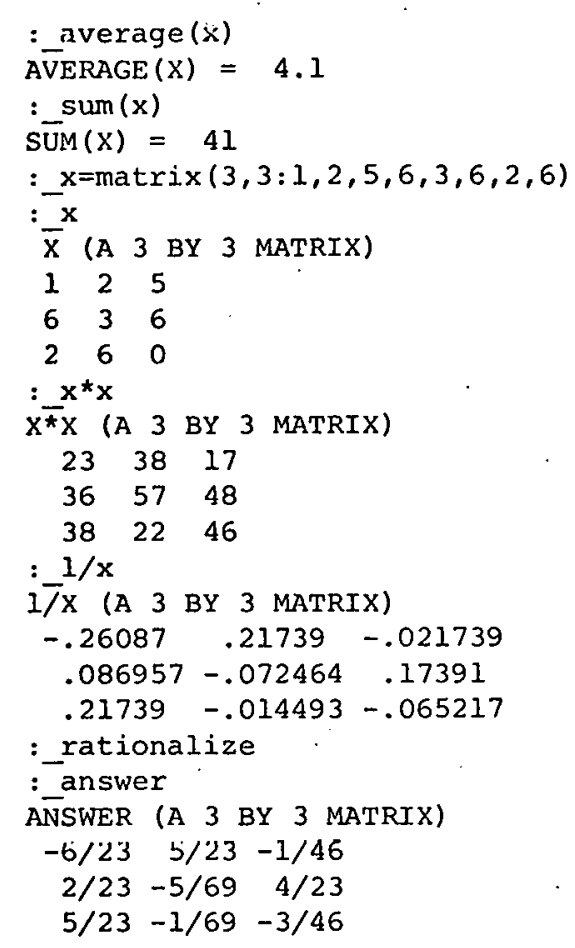

These few lines demonstrate the ease of use of this language. Words such as AVERAGE or SUM are known to speakeasy and carry out the operations that are familiar to everyone. No explanation of their use within the programming language is really necessary. Although definitions of objects such as the matricies and operations such as CUBEROOT presuppose some specialized understanding of these words, the words are used in the conventional way. No explanation to the user who knows these words is needed. It is this naturalness of notation that makes speakeasy so easily learned - there is in fact no educational process at all. It is only necessary to provide the potential users with a few examples so that they feel confident enough to use the system. The processor is designed to be friendly and resilient to misuse. The worst that can happen if an erroneously formed request is entered is a response from the processor indicating a possible cause for the misunderstanding.

The sample session below illustrates some of the common error messages. Note that it is not necessary to restart a calculation if an error is detected, rather it is possible to continue the calculation by reformulating the particular statement that resulted in the exror message. This atmosphere lends itself to learning about the capabilities of speakeasy by using it. The only surprise that is usually expressed by new users is that the processor seems to know more than is expected. (This is merely a reflection of the long evolutionary period to which the system has already been exposed.) 


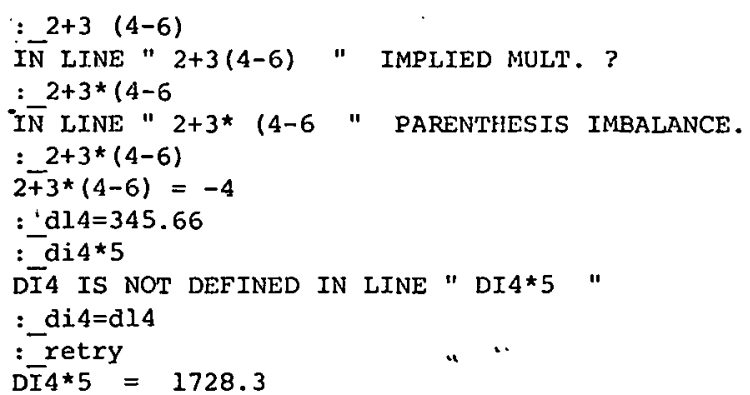

\section{STRUCTURE OF THE SYSTEM}

Speakeasy is designed to work with structured objects and thus provides the environment in which a wide range of distinct operators can be made available. For instance, in the first illustrations an object was defined that is a square matrix. The existence of such an object as an entity within the users definitions means that it is possible to provide all of the operators that are associated with such matrices within the language. Words such as DETERMINANT, TRACE, IRVERSE, and TRANSPOSE, are therefore available. Also the binary operators acquire their conventional meanings when used between two such objects. Similarly, since statisticans make use of the system, the large number of basic operations associated with that discipline such as KURTOSIS and MULTIREGRESSION, are also defined. The power of speakeasy, in fact, rests on the availability of a large number of clearly defined words. The growth in the capability of the language processor has been by the accummulation of large numbers of distinct operations that can be described by well-known words. It is the completeness of the system coupled with the ability to grow to meet new requests that insures a really satisfied user community.

Clearly if a system is to attract a wide audience it is necessary to provide a vast number of operations. To build such operations into a system by the conventional method involving construction of a single large program would necessitate a major and continued programming effort. So laxge and so complex a program would be certain to have innumerable errors and would be plaqued by all of the problenis that relate to such a system. The introduction of any new operation into the program would require major studies of the impact that it would have on the existing system and would be carried out slowly to avoid the possible unforseen impact of the new section of program. It is hardly likely that a really broadly based system could, in fact, ever be constructed as a single program even if it could be clearly specified. It would probably be obsolete before it could be made operational.

Speakeasy was originally conceived of as a system that would marry a simple yet powerful useroriented language to the computational resources available in a large computer complex. The idea was to match the needs of user's by interfacing to facilities available within the machine. It was clear from the outset that the system would evolve under the influence of actual users and that it would therefore have to have growth capability within its structure. In fact the original system was conceived of as two distinct parts. The first was the basic processor designed to analyze through interpretation the request of the users. General operations such as input and output, storage of temporary information and simple definitions were built into this part of the system. In order to aviod inhibiting later growth no attempt was made to build in more than the basic operations. Instead, great effort was expended in the design of a truly library oriented system. A general interface routine was built into the processor. This interface provides the means for extending the language by adding new operations to libraries that are attached to the system while it is in use.

The separation of the processor from the computational libraries provided many assets. The power of this approach cannot be over emphasized. Rather than being forced to develop a complete initial vocabulary it was possible to begin with a relatively primitive system and allow it to grow by the accummulation of new operations. At the same time it was possible to allow the relatively small processor to evolve on its own into a more and more powerful interpreter.

The means of storing defined information is of great importance to a system such as this one. All information must be available not only to the processor but to each of the operators of the system. In Speakeasy a special dynamic storage scheme, called Named Storage ${ }^{2}$, is a component of the processor. This storage facility provides the mechanism for defining and retrieving the structured objects. In this storage scheme each defined object has associated with it a description of its structure alonq with particular values for its elements. Most importantly, the object and its descriptive information can be referenced by name. The name is all that is needed to locate any defined object, to determine everything about its structure and to use it in a calculation.

Each defined object in Named storage has descriptive information appended to it that designates its class, the type of data in its elements and its dimensionality. The allowed ranges for these designators has been made large so that new data types, new classes, etc. can be supported in later developments. Since no computational capabilities are contained in the storage package it is possible to extend the capabilities of Speakeasy entirely through additions to the operators attached to the system.

Individual operators in the speakeasy system are designed to operate on objects defined in Named storage and to produce new objects there. The overall structure of this system is very much like a conventional mathematical system with operators, operands and resultants. The domain of the operators is the space defined by Named storage. It is this quasi-mathematical structure that has led to the ease of development of the overall system 
, $\therefore$

V. THE INTERFACE

In order to allow for coherent yet independent development of the processor and the libraries is necessary to provide an invariant interface between the two. The overall design of the interface between the speakeasy processor and the libraries is of utmost importance. This interface must be flexible, general and reasonably concise. It is obviously also important that it be possible to write the language extensions in a high level language. For speakeasy such an interface was orginally designed in a relatively straightforward way with the intent of allowing user-written Fortran extensions to the language. The concept of the linkable module, i.e., a modular operator library that is accessed through the dynamic LINK facility of the I.B.M. Operating System, proved both straightforward and sufficiently powerful to enable us to construct an extensible system of great power. More importantly, it was possible to document the means of extension and to enlist the aid of others in providing extensions into fields not originally planned.

Speakeasy statement processing is very straightforward. A user written statement is interpreted and calculations are carried out in an oxder corresponding to a standard mathematical hierarchy. Whenever a word is encountered an attempt is made first to find that name in the user-defined variables. If it cannot be located there, then a search of all the linkule libraries that are attached to the system is made. If the word cannot be found as an operator defined in any of these libraries then an error message is issued and processing continues with the next line of user input.

If the name corresponds to a member of one of the linkule libraries, then that operation is dynamically brought into the computer, a description of the operands involved in this particular use of the operator is supplied through the interface and control is transferred to the linkule. 'the linkule, modeled on a mathematical operator, defines its resultant in Named Storage and returns control to the Speakeasy processor. Once its task is complete the linkule is no longer part of the system and can be logically ignored.

For example the following series of statements:

$$
\begin{aligned}
& x=\text { matrix } \quad(3,3: 1,2,3,4,5,6,7,8,9) \\
& y=1,2,3 \\
& t=\text { SOMEOP }(4 * 3, x, y) * 2
\end{aligned}
$$

would result in transfer of control to the linkule SOMEOP with the statement that there were three arguments in the invocation; that the first argument is a scalar number, that the second argument is a 3 by 3 matrix and that the third argument is a 3 component array. The specific values of the elements of each of the arguments could also be obtained. Hopefully, the operator SOMEOP. in turn would define an answer that could later be multiplied by 2 and assigned the name $T$. The operator should represent some meaningful and useful concept involving these three arguments.

Note that the operator SOMEOP resides in a library and is really entirely independent of the processor. Since all information is passed to it and only a resultant is expected from it, the operator can be programmed entirely separately from the processor; it can be tested and made operational without any modification of the speakeasy system.

This rather open-ended approach has obvious advantages. Since each operator is programmed independently there can be no subtle interactions between them. Since any number of linkule libraries can be attached in any session it is possible for individuals or groups to have private libraries of operations. Users are therefore not dependent on the facilities available within the standard system, but may augment the operations there or replace them by more powerful ones.

There is no logical difference between a system linkule and a private linkule. The transfer of private operations into the system is straightforward and only involves proper documentation. It is the ease with which the system can acquire new operations (sometimes whole libraries of operations) that accounts for the large and diverse capabilities of the current version of speakeasy.

\section{A LINKULE EXNMPLE-CUBEROOT}

The Fortran subroutine shown below is a slightly truncated version of a linkule in the standard library. (The truncation is only to avoid obscuring the structure of a linkule for this discussion.) The argument list to the linkule is the standard one for all linkules. It represents the actual interface between the processor and the linkule. All information about the actual invocation of this operation in the speakeasy statement is conveyed through this argument list. (Additional auxiliary system functions for linkules are provided through special subroutines that indirectly use this same argument list.) In the listing below only those arguments that play a role in the linkule are in capital letters. Since the interface is general, no linkule is likely to use the complete argument list. The arguments of importance for this particular linkule are:

NOARGS the number of arguments appearing in the particular call to this linkule;

LOC(1) the location in ALLOC of the first element in the first argument;

KIND(1) the kind of the argument (2 is a REAL number):

KLASS (1) the class of the argument (matrix; array etc.);

NROWS(1) number of rows in the argument;

NCOLS(1) number of columns in the argument; ICLRES the subroutine call that defines a new object in the allocator; the functional value is the location of that object in ALLOC:

ANS the name that is to be assigned to the results of the linkule. 
FUNCRIOY LINKUI, (ANS, illoc, NORRGS, icol, icom,

idom, acc.

larg,val, ival, KIND, KJASS, NROWS, NCOLS, nels,

2LOC, MILOC, ICLRES, iquery, ifree, iqures, alias)

IMPLICIT R: $A L * 8(A-H, 0-2)$

DIMENSION KIMD (1), KLASS (1), MRONS (1), NCOLS (1)

HLoc (1), AlJOC (1)

LINKUL $=0$

C CHECK FOK PROPER NUMEER OF ARGUMEITS

IF (NOARGS.NE. 1) GO 'IO 9001

CHECK THAT ARGUMENT IS DEFINED.

IF (KIND(1).EQ.0) GO TO 9002

CHECX THAT ARGUMENT IS REAL.

IF (IABS (KIND(1)) .NE.2) GO TO 9003

DEFINE RESULTANT TO MOCK ARG(1) STRUCTIRF.

50 LOCANS $=$ ICLRES (ANS , 2 KLASS (1), NROWS (1), REOLS (1), LOC

c PERFORM OPERATION ON EACH ELEIIENT OF ARGUMENT.

c

NELS $1=N E L S(1)$

DO $100 \mathrm{~N}=1$,, HELS

100 ALLOC (LOCANS+N-1)=DCUBRT $(\operatorname{ALLOC}(\operatorname{LOC}(1)+N-1))$ LINKUL $=1$

RETURN

ERROR RETURNS

WRONG NUMBER OF ARGUNENTS

g001 CALL TMESS ('SCUBEROOT KUST HAVE I ARGUNENT $\$$ ') RETURN

C ARTUHENT IS NOT DEFINED.

9002 CALL TMES (ARG (1), '\$IS NOT DEFINED.\$') RETURN

ARGUMEIST IS NOT REAL.

9Oก 3 CAII TMEE(ING(1), ' SMUST BE REAL.\$') RETURN

END

In the above routine, DCUBRT is a standard routine available in the Fortran library. It is designed to carry out the computation of the cube root of a scalar. This linkule is an interface to that routine and makes it available to speakeasy. From the linkule writer's viewpoint this routine can be viewed as a standard Fortran function routine that is called by the speakeasy processor when the word CUBEROOT is encountered. Error checking, error messages and array processing facilities are built into this linkule. The

- linkule writer has the responsibility of seeing that checks are inade to insure that the linkule is properly applied and that appropriate exror messages are issued. The functional value (LINKUI=1) is used to indicate whether or not the operation was successfully completed.

The description of the linkule as given above is brief and incomplete. A complete description is yiven as a chapter in the Speakeasy Reference Manual ${ }^{3}$. That the description there is adequate has been verified by the ability of numerous eople to construct language extensions with no ther information.

\section{GROWTH BY ACCUMULATION}

That Speakeasy provides an environment for growth is clear. Users of the system create operations that are lacking in the overall system to meet their own needs. In addition, since an audience for these new features exists, they are usually anxious to make them available for use by others. The growth of the overall computational capabilities of the system is therefore, to a large extent, in the hands of the users of the system. The Speakeasy Center, at Argonne National Laboratory, now plays the role of development and maintenance center and at the same time acts as the distribution center for externally developed contributions. Several major packages are now contained within the speakeasy system as part of its standard system libraries.

For example EISPACK ${ }^{4}$ is a well documented, state of the art package of routines designed to carry out eigen-analysis on a wide variety of types of matrices. Speakeasy's words EIGENVALUE and EIGENVECTOR are interfaces to that package. They provide the power of this advanced system directly to the users of speakeasy. The interface automatically selects that path through the package of routines that is appropriate for the matrix involved. The following few lines of speakeasy illustrate this.

$: t=\operatorname{smat}(3,3: 1,2,3,4,5,6)$

$: \_t$

T (A 3 BY 3 MATRIX)

$12 \quad 2 \quad 4$

235

456

:_eigenvalues ( $t)$

EIGENVALUES ( $T$ ) (A VECTOR WITH 3 COMPONENTS)

$$
\begin{array}{lll}
-1.5066 & -.057396 \quad 11.564
\end{array}
$$

$:$ x=matrix $(3,3: 1,2,5,6,3,6,2,6)$

$: \mathrm{x}$

$X$ (A 3 BY 3 MATRIX)

$\begin{array}{lll}1 & 2 & 5\end{array}$

$\begin{array}{lll}6 & 3 & 6\end{array}$

260

:_eignevalues $(\mathrm{x})$

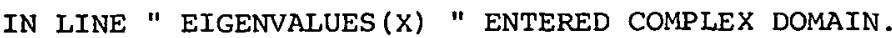

:_domain complex

: retry

: EIGENVALUES $(X)$ (A VECTOR WITH 3 COMPONENTS)

$-3.2471+1.6146 i-3.2471-1.6146 i \quad 10.494$ 
John H. Reynolds of COMSAT Laboratories has provided users with one of the most powerful interactive graphics packages currently available. It is distributed as part of the standard system and continues to evolve in power with each new release. The examples below are produced by entering just a few lines on a Tektronix terminal.

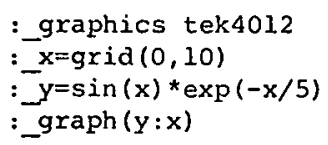

produces the first curve and the axis labeling

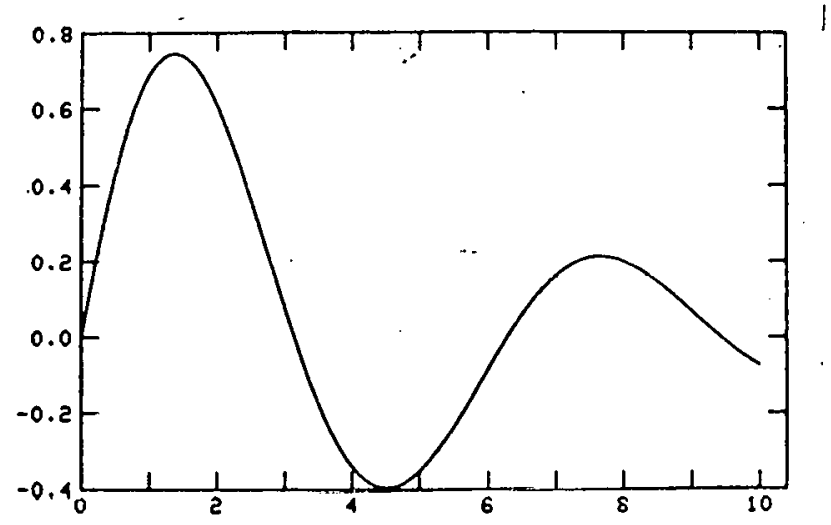

:_adgraph (deriv $(y: x): x)$

adds the second curve to the original display.

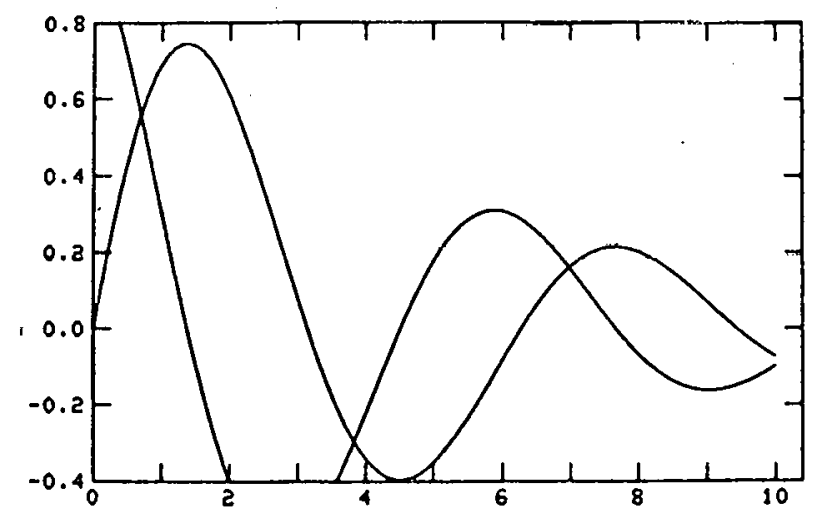

A complete econometric package has been added to speakeasy at the Board of Govenors of the Federal Reserve Board. Speakeasy was originally accepted by the economists at the Board because of its built in matrix algebra. When it became known that the power of the system could be extended to include access to locally produced data bases, then it was decided to enlarge speakeasy's vocabulary to make it into an econometric language. A team of programmers undertook the development of a language extension referred to as FEDEASY ${ }^{5}$ that contains operations of great interest to their own users. This library is also destributed as part of the speakeasy system and is heavily used at many places.

\section{CURRENT STATUS OF THE SYSTEM}

Speakeasy is an operational computer system. It is currently in use in about 100 sites and has several thousand users. The audience consists of scientists, engineers, statisticians, economists and a gencral studert population. It is available for use under most I.B.M. Operating Systems. Preliminary translations to DEC, UNIVAC and FUJITSU machines exist. Adaptations to other machines are currently underway. Although few operating systems have the LINK feature described above, it has been possible to adapt the basic concept of a linkule to other systems and to obtain a logically equivalent system.

The growth of the speakeasy audience now seems assured. There are now sufficient users of the system to justify the creation of special libraries of operations tailored to specific groups. The growth of libraries of roulines such as FEDEASY should become more common in the future. since the power of the system rests in the completeness of facilities available, this growth will in turn attract new sets of users.

\section{REFERENCES}

1. S. Cohen, "Speakeasy - A Window Into a Computer", AFIPS Conference Proceedings 45 (1039) 1976

2. S. Cohen, Named storage, Argonne National Laboratory Report ANL-7021, April 1964

3. S. Cohen and S.C. Pieper, The Speakeasy-3 Reference Mánual, Argonne National Laboratory Report ANL-8000, May 1976

4. B. T. Smith, J. M. Boyle, B. S. Garbow, Y. Ikebe, V. C. Klema and C. B. Moler, Lecture Notes in Computer science, vol. 6 springer Verlag, New York (1974)

5. Econometrica, Program Announcement, 45, I (1977) 